\title{
Visual Surplus of Seeing Play in ECE: Beyond the Ontologic Trap?
}

\author{
E. Jayne WHITE | oRcID : 0000-0002-1467-8125 \\ Professor; Royal Melbourne Institute of Technology University, \\ School of Education Melbourne, Australia \\ Jayne.white@rmit.edu.au
}

\begin{abstract}
Play holds a precarious status in early childhood education curriculum and even more so in pedagogy. Misaligned with adult-ceatred discourses that seek to name and frame learning according to established curriculum ideals, the educators' quest is to capture evidence of leaving in an ontologic trap that binds teachers in the service of the state and its priorities. Yet, an increasing body of dialogically inspired research seeks to suspend such authoritative strongholds by revealing the nuanced state of play that exceeds such framings. In this paper the dialogic notion of visual surplus is specifically exploited through the deployment of 360 degree footage filmed in an ECE centre, and dialogues about what is seen, generated as part of a larger study. Through such excess playful encounters with and about young learners - often in spite of, not because of, well-meaning adult interventions - make a mockery of those claims that are made by adults through their play. Instead, a democratic agenda is set for play as a series of alteric as well as agentic events that lay bare the trap and attempt to escape it.
\end{abstract}

\section{Keywords}

play - early childhood education - Bakhtin - visual surplus - 36o degree camera

\section{Introduction}

I have come to this classroom of three- and four-year-olds to uncover their secrets, but the children seldom reveal them in conversation. Instead, 
they change identities and burrow into hidden places: they speak in code and flee from invisible foes; they manufacture problems whose resolution depends on judgments I cannot anticipate. (Gussen-Paley, 1988, vii).

Enter into almost any formal early childhood education (hereafter described as 'ECE') classroom in the Western world and you will see children at play. Playbased leaving through observation underpins most ECE curriculum in the West - inspired by the work of key contributors to the field such as Jean Piaget, Mildred Parten, and Lev Vygotsky. Teacher preparation programs will typically introduce students to the idea that play is the primary vehicle for pedagogical engagement with very young children and it should therefore be taken very seriously by teachers. They will be told that their role is to exploit the potential of play for the promotion of valued learning through observation and assessment, using received frameworks and theories for categorisation such as stages of play or mediated learning. Upon graduation they will become staunch advocates of play as a window to achieving certain developmental, social and cognitive goals (Whitebread, 2018) by providing play-based learning environments that will facilitate such learning based on their expert interventions (Arthur et al., 2017). Armed with an arsenal of teaching strategies, these graduates will set out to 'scaffold' play in the service of education - orienting children's 'activities' towards desirable goals through questioning, re-directing and manipulating play frames that claim to be discoverable through their everyday experiences with children (Fleer, 2010). If these children are very lucky, their teachers might occasionally play with them too - but such investment will be carefully curated into a sanctioned curriculum experience that can only be granted value on adult terms. Play of any other nature is largely dismissed, shut down or downright ignored seldom finding its way into assessment or planning records that legitimise learning.

Yet, as Vivian Gussen-Paley (1988) pointed out many years ago, children's play often exceeds adult parameters. It is complex, mysterious and elusive - a "virtual recapitulation of life's enigmas" - through which children make sense of their worlds, on their own terms. While her approach to understanding their play has been critiqued by Matusov (2011, see also Sidorkin, 2002) as authoritarian because certain ideas are ultimately posed by the teacher, there is no doubt that Gussen-Paley's rich narratives lay bare the dialogic nature of play and its challenges for ECE teachers. Children's play depicted on dialogic terms is an ontologic event that implicates adults whatever outsider-insider position they take in this space (Marjanovic-Shane \& White, 2014). It can be both confusing and confronting for adults who are on the outside of the play, as discovered by researcher Rachel Rosen - who literally became the 'butt' of the joke 
for children in a UK ECE centre. It can be equally challenging for adults who try to keep up with children by lurking within their play (Edmiston, 2010) - especially so when it becomes apparent that their very presence is altering the script (Tam, 2012) or shutting it down when it becomes uncomfortable for the adult (Gol-Guven, 2016). The problem this paper sets out to pose, then, is not that play in ECE settings should be dismissed as a highly valuable pursuit for children's learning - far from it! Rather, the intention here is to de-throne the all-seeing, all-knowing ECE teacher in determining and framing its worth. An argument is posed that the tight coupling of play with pedagogy may in fact corrupt the central tenet of play as necessarily and delightfully ambiguous. As outlined by the late Brian Sutton-Smith (1997), when categorised only against sanctioned curriculum goals, play may in fact loose its complexity as well as its magic. Unleashed from these strongholds play may be granted primacy in its own right, and teachers can celebrate its mystery as well as its madness (Cohen, 2011). To illustrate this possibility, the paper that unfolds will take a dialogic route to the understanding of play in contemporary ECE settings. Based on a recent study of an ECE centre in Aotearoa New Zealand, using dialogic methodology, play is seen in this paper as taking place beyond, perhaps even in spite of, the scaffolding presence of the teacher and well beyond any pedagogical play framing that might be imposed. A complex, highly sophisticated peer group of learners emerge in this alternative viewing - where learning of a different nature arises out of misunderstandings, mischievous engagements and, as we shall see, deliberate misalignments on the part of children as they navigate their way through, and often in spite of, the ECE curriculum and its well-meaning teacher.

\section{A Dialogic Route to Understanding Play}

Bakhtin described play as something that happens only when 'the footlights are off' (1968, p. 235). By this he meant that play can be characterised by its freedom from constraint and its associated ambivalence to a sanctioned (observing) audience, authority or intervention. For this reason Cohen (2011) argues that play may in fact be very unattractive to ECE teachers because the script can be offensive or seem nonsensical to the adult interloper. Perhaps for this reason only a handful of ECE scholars have taken up these ideas in their research with young children at play in ECE with the aid of dialogic methodology. Taking a dialogic route is not a journey to be taken by those wishing to generate certain outcomes (White, 2016).

By its very nature dialogism is an encounter with the ambiguous because it is oriented to social spaces 'in-between', with ethical accountability for how 
others are represented. Dialogic research sets out to understand events of becoming as ideological encounters that are inter-animated by all forms of language (not just that which is spoken) and their interpreted, lived, meanings in co-constituted everyday events. As Shafton explains: "Dialogic discourse analysis provides us with the tools to describe the relational dynamics of real-life classroom interaction" (2019, p. 11). The quest of the dialogic researcher is therefore to earnestly try to interpret what is being offered based on what they can see as an effort of knowing which is only one amongst a chorus of perspectives but which can offer visual surplus to the interpretations that can be made.

Accommodating for the shaping potential of representation lies at the centre of visual surplus which Bakhtin describes as an excess of seeing that is available to the outsider observer that is not evident to those at the centre of the event (1990, p. 5). In his book "Speech genre and other late essays" Mikhail Bakhtin upholds the work of the eye in this regard as "not only the first but also the last authority, when the visible was already enriched and saturated with all complexity of thought and cognition" (Bakhtin, 1986, p. 27). Bakhtin goes on to provide some clues as to how this might be done through engagement with language in its broadest sense - in discourses that reveal the ideologies at play: "every discourse betrays the ideology of its speaker; every speaker is thus an ideologue and every utterance an ideologeme" (Bakhtin, 1986, p.101). His provocation extends to engagement as an ambiguous encounter that can be better appreciated, but never fully grasped, through a chorus of insights that are based on a series of competing ideologies at play in everyday events. Looking at play through visual surplus disrupts the idea that any representation narrative, virtual, photograph or movement - represents all that there is to be known on the subject. It is always and only a visual field, a visual perspective that is loaded and imbued with ideological interpretation and, one might say, manipulation. Whether it is video taken from the visual fields of infants or researchers, whether indeed there are dialogues about these visual fields and even when, there are dialogues about those dialogues - there is always only a partial view. Its utility in the social space is what grants play its truth, untruth or perhaps post-truth status - suggesting that there are great plays with whose truth is constructed, by whom and for what purpose. How play is seen in the examples that follow demonstrate this complexity by exploiting visual methods in the promotion of polyphonic viewings (White, 2016).

Dialogic studies undertaken in ECE settings specifically highlight the various ways young children in early years institutions are strategically orienting their play within curriculum (Tallant, 2017; Rosen, 2016) manipulating their engagements in sophisticated 'double-voiced' ways to respond to teachers and their peer group as discrete groups with competing agendas (Cohen, 2011; Tam, 
2012; White, 2011, 2013, 2016). These studies radically expand on notions of children's play when dialogically encountered beyond, and sometimes in resistance to, the intervention of the ECE teacher; but they are primarily based on researcher narratives in the absence of teacher points of view. Taking Bakhtin's expanded view of language beyond mere words and exploiting the potential of visual surplus with teachers in contemplation of their seeing encounters, the study that follows reports on teachers well-intentioned manoeuvres concerning their understandings of young children's play when Bakhtin's concept visual surplus is operationalised. While this account does not avoid the ontological trap described by Matusov (2009) when interpretations are imposed by those in authority (in this case researchers and teachers), it does illuminate the revised viewings of play when "seeing (contemplating) and supplementing through creative thinking" (Bakhtin, 1986, p. 159) as visual surplus rather than as truth or platitude.

What better place to locate a study of play through visual surplus than in a mixed age New Zealand ECE setting underpinned by a socio-culturally oriented curriculum that calls upon teachers to represent learning in play? New Zealand is one of the few countries in the world where representations of children are play are permitted to be recorded by researchers for research purposes, or shared in the public domain for others to view (Rutanen et al., 2018). The examples provided here draw from a larger study of two preschools that spent two years exploring visual surplus in the pursuit of pedagogical understanding concerning a flux of younger children entering their play spaces (White \& Redder, 2019). While these teachers saw themselves as experts in the field and were fully qualified with several years of experience, they were unsure of how to provide an effective learning environment for younger children whilst also supporting the learning of their older peers in their play-based environments. Importantly for them, they were also uncertain about how to talk about their learning in sanctioned ways, while upholding the priorities of diverse learners.

In their quest to procure a meaningful curriculum experience for their students, teachers across this and another ECE setting committed to a two year investigation which invited them to engage with dialogic concepts that significantly disrupted their prior knowledge about play as a teacher mediated activity. They asked a series of research questions in framing their quest - these included "what do dialogues 'look like' for these learners?", and :what is the role of the teacher in these?". They agreed to wear video glasses to film their 
close-up encounters as pedagogy; Parents agreed to allow filming of their children using a Swivel camera that would track two year-olds as they went about their play;, and both parents and teachers consented to be filmed within the wider learning environment using a 360 degree camera. Taken together these visual fields constituted visual surplus from a range of vantage points that were coded by the teachers and researchers independently; and which formed the basis of subsequent teacher dialogues (which took place during a series of meetings with researchers) concerning what could be seen, by whom and what it might mean for their understandings of these learners (for an example of what this looked like see https://www.waikato.ac.nz/age-responsive/ what-do-teachers-do-and-say-with-two-year-olds). Significant shifts in their pedagogy took place as teachers and researchers began to 'see' more based on a combination of reading, watching and analysing the polyphonic footage based on multiple vantage points.

In the example that follows we focus on both the 360 degree camera as important sources of visual surplus in spontaneous play events that characterise the kinds of valued learning experiences that are provided for young children in many ECE contexts in New Zealand (and in other parts of the world that advocate for 'play-based' curriculum). While one cannot assume that any certain camera lens necessarily portrays certainty about its significance to play, the 360 degree camera holds special status here. It was hung in the outdoor play area, without any mediation or manipulation. Its wider angle proffered a view of the wider play space and what was happening in it - often outside of the teachers or the researchers gaze. Its visual surplus re-orients vantage points from which to understand learning and its potential for very young children. Within the constraints of the ECE space, no framing is possible and all is laid bare to see. When viewed retrospectively it becomes possible to see how children navigate playfully in and between both insider and outsider axiologic spaces - often in spite of rather than because of adult efforts of engagement.

In the 360 degree example that follows we can see the outdoor area of the mixed age ECE setting in the late morning of a sunny winter's day. Both teachers are in the sandpit (left of screen) holding a hose because the children have asked for water in the sand and are told that only the teacher will fill their bucket so as not to waste water or get wet (and cold). 


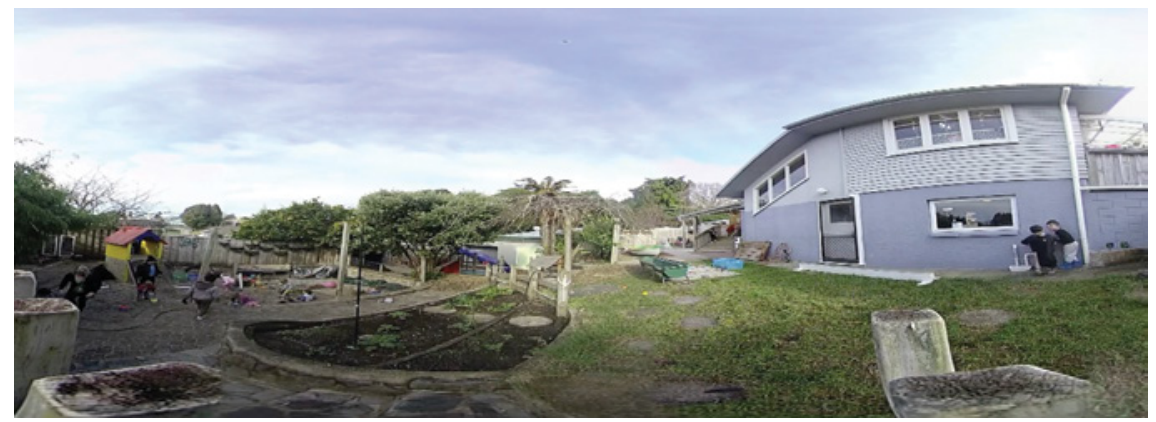

FIGURE 1 Our two four year-old players are at the water trough (right of screen). They are filling up their mouths with water and laughing heartily. Player 1 holds the water in his mouth and walks to the sandpit.

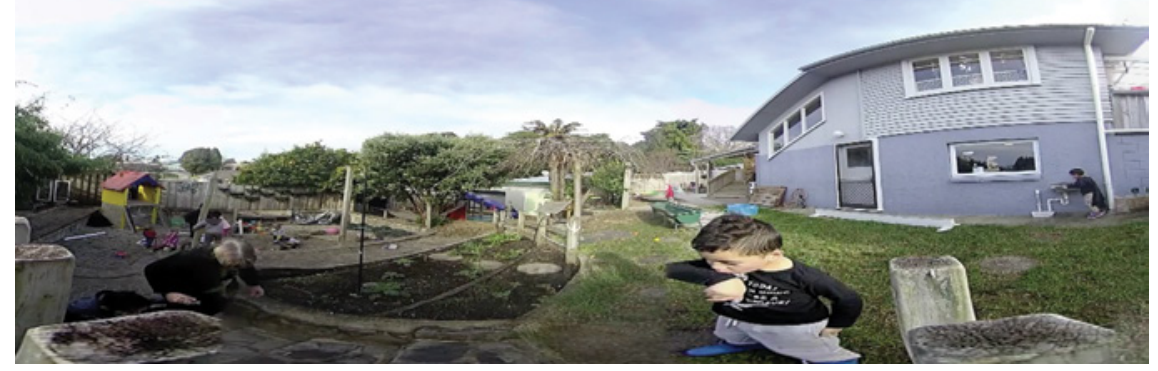

FIGURE 2 On his way to the sandpit a teacher walks close by. Player 1 holds his arm over his mouth. He then walks around the other side of the grassed area and enters the sandpit from the right hand side.

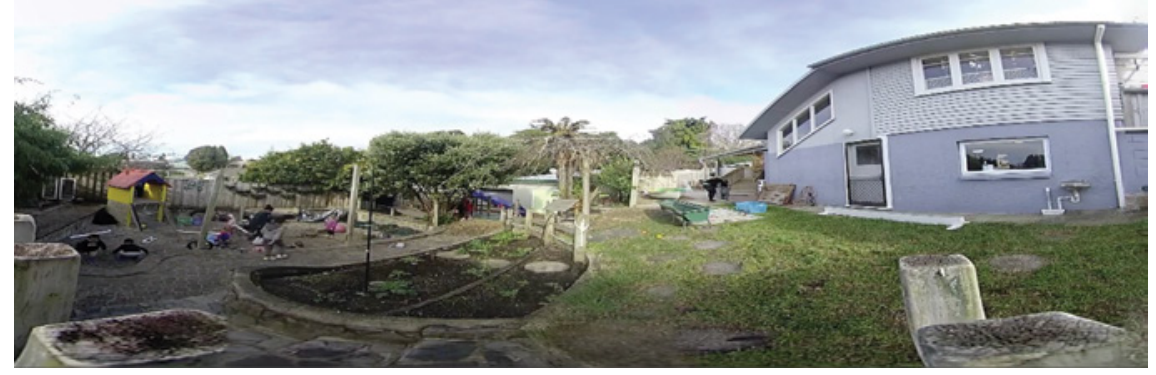

FIGURE 3 Player 1 is joined by Player 2. The teacher is out of sight and they both spit the water into a bucket they have buried in the sand, laughing and shouting out "I shoot it"! They return to the water trough and repeat the scenario several times. Player 2 invites a younger peer to join them shouting "lets go", whereupon the peer runs up the stairs with them. At this same time the teacher has returned to the scene and calls out "Hey Batman, Hey Spiderman - where are you off to?" 


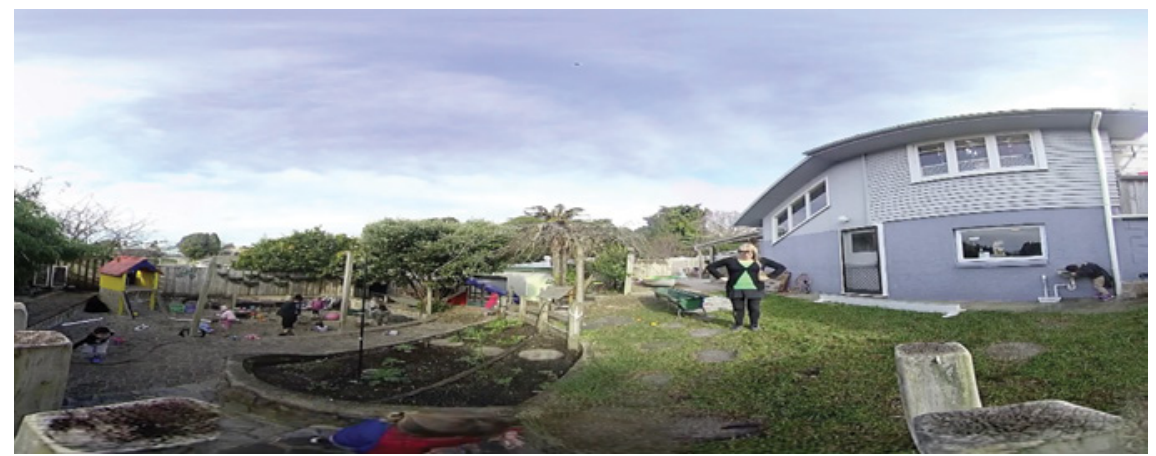

FIGURE 4 Player 1 returns to the water trough shaking water off his hands as he walks past the teacher. "Oh you're a dinosaur" says the teacher and mimicks the shaking hands. "Is that what these are for?" says the teacher waving her hand. Player 2 doesn't answer and walks to the water trough while Player 1 passes by with his mouth full of water, and hand over mouth.

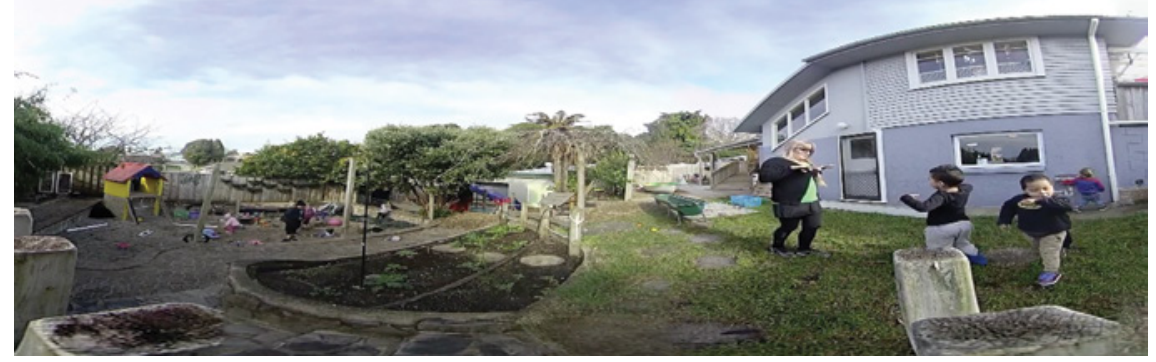

FIGURE 5 Teacher follows Player 1 to the water trough where he is pushing the water out and says "now you have to drink it", which he does. She then tells him to stand back so that the younger peer can have a drink. She rearranges the positioning of Player 1 and pushes the tap for the younger peer, explaining "he needs to have a drink". The two year old has a drink and the teacher says "Oh yum. Thank you" as he returns to the sandpit with Player 2.

Discoverable as a result of the visual surplus offered by the 360 degree camera, our re-readings and dialogues as a group of teachers and researchers what were we to make of this curious event of play? Was its purpose to fill the bucket in spite of the rules, was it some sort of socio-dramatic role play between superheroes that we were not privy to or was it simply an act of defiance? Clearly there was an intention to persist with the play agenda which went against the rules - perhaps it was this very fact that made it so joyful? That the teacher did not see it unfolding at the time, however, provides 


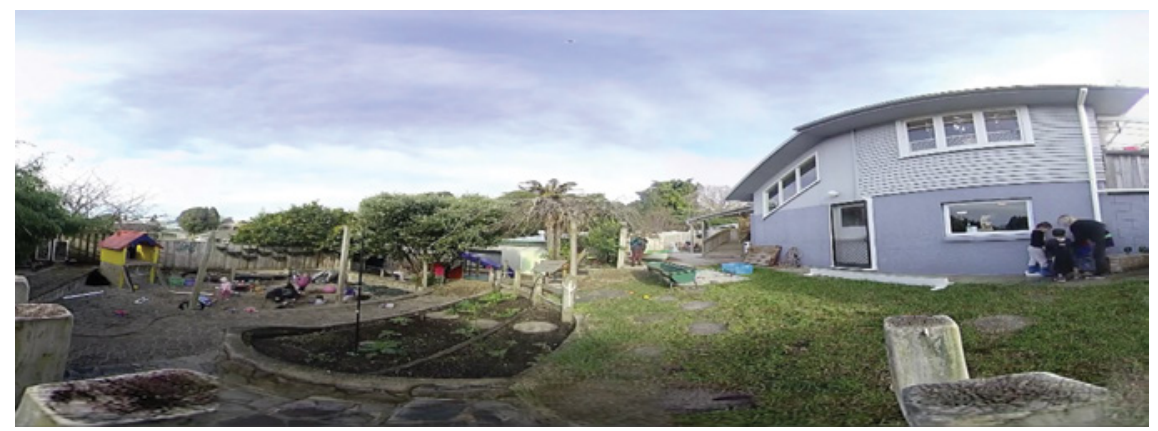

FIGURE 6 All three players return to the water trough where the teacher continue to instruct them on how to take turns to get a drink. Player 2 says "I'll push it" and leans around towards the younger peer. Teacher says "yeah but then he can't get a drink - look here". She pulls the two year-olds sleeves up while the older Players stamp their feet. "Oh nice. Thank you" says the teacher as she orients the younger peer away from the water trough. Player 2 then has a drink and runs to the sandpit as the teacher says "Thank you R". Player 1 watches as they walk away with the teacher.

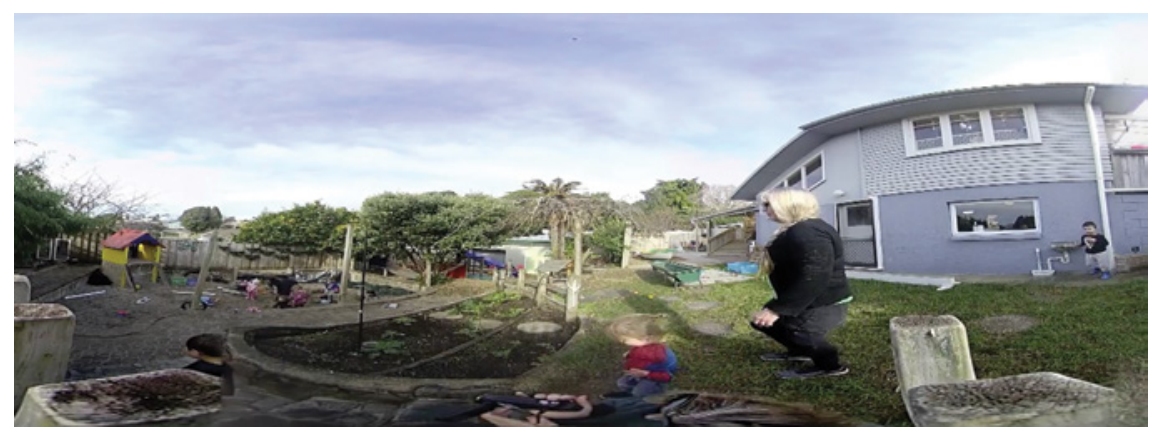

FIGURE 7 Quickly Player 1 fills his mouth with water again and follows the teacher back to the sandpit.

us with clues as to the way this play was mis-read and, with visual surplus, re-read - leading to significant adjustments in both understanding of play and its learning potential. Importantly, this visual surplus provided a means of teachers examining the impact of their own pedagogy on what transpired.

There were many such acts throughout the study - often involving younger children in quite sophisticated ways and generating alternative readings of play. During our dialogues at the end of two years of such visual surplus encounters with play, the teachers reflected on their insights of events such as these as a source of inspiration and insight: 


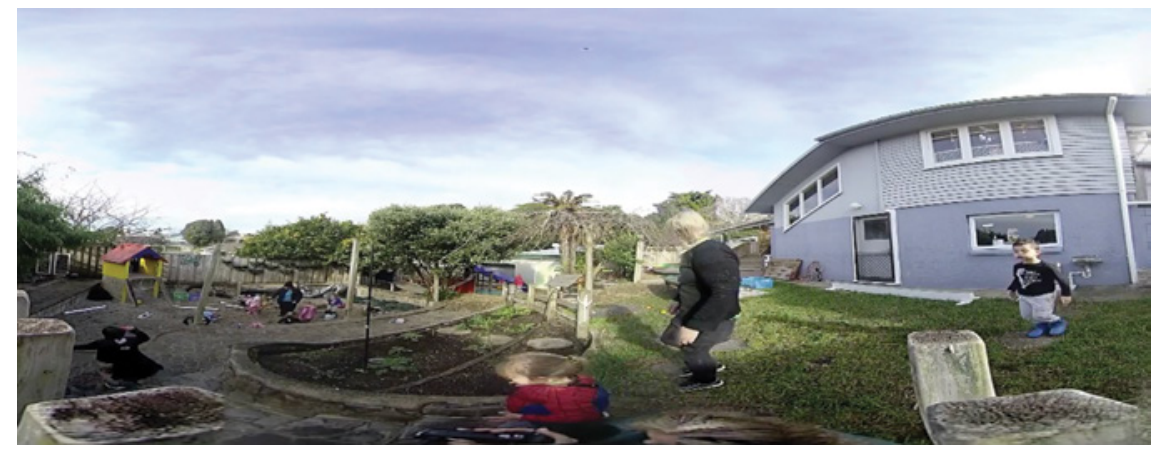

FIGURE 8 This play continues as both older Players take turns spitting water into the bucket over several episodes until they are satisfied that the bucket is sufficiently full. This takes place over a sustained period of 30 minutes whereupon the Players laugh loudly as they dance around the bucket with sticks before going inside for group time.

"We have noticed that they will change their play when they see that we are watching them. I would have previously seen these acts as naughty, but now I see them as magical... We noticed peers breaking the rules and modelling this for the two year-olds who, by association, were given exclusive entry into the game through participating in this manner.... We recognize that the dialogues that take place in play when we are not close are important too; but they are also important for peers if they know that what they are doing deviates from what the teachers expects of them. So teachers play an enormous moderating role but also as a means of enabling the joy of deviating from the rules..."

Did it matter if we were reluctant, perhaps even unable, to name and frame this play we asked ourselves? That there was such a deliberate act of rule breaking that took place right under the teachers nose suggested an act of alterity on the part of these learners - even though we didn't fully understand their intent, it was clear from the actions of these children that they did not want or need our approval or intervention. From a dialogic standpoint, we were able to celebrate this rather than blame the teacher for her pedagogical oversights or lament a more productive play agenda. The capacity of these children to overcome the interference of the teacher through quiet acts of resistance transformed play of this nature into a series of anarchic events of becoming that far exceeded notions of learning accessible in traditional play frames. Instead we came to see that such forms of play offered rich potential for a more sophisticated understanding of young learners as creative, humorous and subversive members of a society that adults may never fully grasp but which hold potential for insights concerning the importance of alterity for learning: 
"WE can see that alterity is so important for... agentic learners. We can see how the same act can have so many different meanings and that we need to try to understand these. Sometimes this leads to intersubjectivity and sometimes it doesn't, but it's the effort of trying that we are focusing on now, and we do this in partnership with families who can help us..."

Over the course of the study, teachers began to see, and consequently value, more and more of these play events as learning. What they didn't see before was revealed to them through visual surplus. One teacher asked "Why did we notice the game this time and not last time. That's interesting". Another teacher explained "We are now more comfortable with the uncomfortable - even dialogues about diddles!". They revised several of their teaching strategies to accommodate these insights. One teacher explained: "This involves risk taking in terms of how far we will allow things to go. We have developed a greater tolerance for a lack of structure and rules...Two years ago I would have shut that down in a heartbeat but now, I let it go as much as I can". While another suggested an increased role for the peer group in play:

"There are times when we tolerate the game, actively stay out of the game, curtail the game and maybe even totally destroy it in our desire to be at the centre of dialogue. We have also seen that peers will play a moderating role here. We now see that we are not the only dialogue partners here! ... We have a dialogic attitude to our work now and this means that we value the perspectives of others and are less inclined to settle for less".

These insights were reflected in their revised approaches to assessment. Teachers began to write learning narratives that celebrated alteric play as much as activities or interests that they valued. They remained open to the potential of visual surplus through sharing insights and looking for more than just play frames that matched the curriculum or their own priorities:

"We have recognized that learning takes place well beyond the rules and we are seeing those alteric moments as something to celebrate now. It has given us a license to document those moments. In the past you have those children who might be doing things that go against the grain but you would never document that whereas with a dialogic perspective you can actually underpin that as crucial learning. We've had a good laugh with [child's] mum because we talked about he had basically told me to 'naff off' when he did the haka. Now would you have done that in the 
past? No way! Even just the understanding of the significance of this act in that moment has been key."

\section{Implications for Early Childhood Education}

Did we avoid the ontologic trap of framing play for ourselves in these discoveries? Perhaps not entirely. By its very nature, every play encounter will be drenched in combinations of interpretations and perspectives - as players test out authority, counteract, translate and undermine certain 'seeings' in favour of others according to the strategic priorities of the players and those who seek to understand their play. Teachers in the ECE contexts in which children now play every day are seriously implicated for their responses and, as Bakhtin explains, there is no alibi. Although we never discovered the meaning of the water spitting event described in this paper (although it would have been very interesting to ask the players, but that is another story) this play event did nonetheless - along with the many other insights we saw through visual surplus - open up potential for exploring our interpretations of play beyond dominant framings. Such seeing and re-seeing is undoubtedly an ontologic exercise, yet as Spyrou, Rosen and Thomas Cook point out, "questions of ontology lie at the heart of childhood studies" (Spyrou et al., 2018, p. 7). Understanding play as an ontologic event of visual surplus in ECE calls upon teachers (and researchers) to account for their depictions of children as entanglements with the discourses in which they are produced rather than framing the play itself. That children do so with such ease and finesse is surely worth celebrating! That these teachers are prepared to go beyond the enframing traps that the sector has set them (and children) up for is equally inspiring. Perhaps, with visual surplus in play, we can at last begin to unleash the certainties of learning beyond the constraints of teaching (Biesta, 2017; White \& Lensmire, 2016). To do so would allow us to reclaim play in ECE contexts as a political, democratic act of agency and alterity for the players and, if we are open to its surplus provocations, for ourselves. I am in no doubt that this is exactly what Vivian Gussen-Paley would have us do!

\section{Acknowledgements}

This work is dedicated to Vivian Gussen-Paley who passed away during the writing of this paper. Vivian understood better than most the importance of children's play in ECE and the ontological challenge play poses for ECE 
teachers across the globe. The author wishes to also acknowledge the generous Teaching, Research \& Learning Initiative Funding that made the reported study possible - this playful dialogic encounter with ways of seeing as meaningful research was made possible only in collaboration with a group of crazy, wonderful and brave teachers who were willing to 'give it a go'!

\section{References}

Arthur, L., Beecher, B., Death, E, Dockett, S. \& Farmer, S. (2017). Programming and Planning in Early Childhood Settings (7th Ed), Cengage Learning Australia.

Bakhtin, M. M. (1981). The Dialogic Imagination (M. Holquist, Ed., C. Emerson \& M. Holquist, Trans.). University of Texas Press.

Bakhtin, M. M. (1986). Speech Genres and other Late Essays (C. Emerson \& M. Holquist (Eds.), V. W. McGee (Trans.). University of Texas Press.

Bakhtin, M. M. (1993). Toward a Philosophy of the Act V. (Liapunov \& M. Holquist, Trans., (1st ed.). University of Texas Press.

Biesta, (2017). The Rediscovery of Teaching, Routledge.

Cohen, L. (2011). Bakhtin's Carnival and Pretend Play, American Journal of Play, 4(2), 176-203.

Edmiston, B. (2010). Playing with Children, Answering with Our Lives: A Bakhtinian approach to co-authoring ethical identities in early childhood. British Journal of Educational Studies, 58(2), 197-211.

Fleer, M. (2010). Early Learning and Development: Cultural-historical concepts in play. Cambridge Press.

Gol-Guven, M. (2016) Who is Holding the Longer Stick? The power of adult presence on children's play, International Journal of Play, 5(2), 123-127.

Gussen-Paley, V. (1988). Bad Guys don't Have Birthdays: Fantasy play at four. The University of Chicago Press.

Lensmire, T. \& White. (2017). A 'Wrong-Headed' Reading of Carnival, Democracy and Education. Knowledge Cultures, 5 (3). 11-22.

Lobok, A. (2012). Preschool Education Bullied: An experiment in establishing dialogue with a kindergarten educator. Journal of Russian and East European Psychology, $5^{\circ}$, (6), 92-114.

Marjanovic-Shane, A. \& White (2014). When the Footlights are Off: A Bakhtinian analysis of play as postopok. International Journal of Play.3, (2).

Matusov, E. (2009).Journey into Dialogic Pedagogy, Nova Sense Publishers Ltd.

Spyrou, S., Rosen, R., \& Cook, D. T. (2018). Introduction: Reimagining Childhood Studies: Connectivities...Relationalities...Linkages....”. In S. Spyrou, R. Rosen, D. T. Cook (Eds.), Reimagining Childhood Studies. Bloomsbury Publishing. 
Tallant, L (2017) 'Embracing the Carnivalesque: Young children's humour as performance and communication.' Knowledge Cultures, 5 (3). pp. 70-83.

Tam, P. (2012). Children's Bricolage under the Gaze of Teachers in Sociodramatic Play, Childhood, 20(2), 244-259.

Rosen, R. (2016). Imagineries of Childhood and Neo-liberal 'Value': Double-voiced responses to violently themed imaginary play. International Journal of Early Childhood, $47 \cdot(2)$.

Rutanen, N., de Souza Amorim, K., Marwick, H. \& White, E.J. (2018). Tensions and Challenges Concerning Ethics on Video Research with Young Children - Experiences from an international collaboration among seven countries, Video Journal of Education and Pedagogy. https://videoeducationjournal.springeropen.com/articles/ 10.1186/s40990-018-0019-x.

Skaftun, A. (2019). Dialogic Discourse Analysis: A methodology for dealing with the classroom as a text. Dialogic Pedagogy: An International Online Journal, 7., pp: A143A163, https://doi.org/10.5195/dpj.2019.277.

Sidorkin, A. M. (2002). Learning Relations: Impure education, deschooled schools, \& dialogue with evil. P. Lang.

Sutton-Smith, B. (1997). The Ambiguity of Play. Harvard University Press.

Whitebread, D. (2018) Play: The New Renaissance, International Journal of Play, 7 (3), 237-243.

White, E.J. (2011). 'Now you see me, now you do not': Dialogic loopholes in authorship activity with the very young. Psychology Research, 1(6), 377-384.

White, E.J. (2013). 'Are You 'Avin a Laff?': A pedagogical response to Bakhtinian carnivalesque in early childhood education. Educational Philosophy and Theory, 46 (8), 898-913.

White, E.J. (2016). More than Meets the 'I': A Polyphonic Approach to Dialogic Meaning-making. Video Journal of Education and Pedagogy. http://videoeducation journal.springeropen.com/articles/10.1186/s4099o-016-0002-3.

White, E.J. (2016), Introducing Dialogic Pedagogy: Provocations for the Early Years, Routledge.

White, E.J. (2016). A Feast of Fools: Mealtimes as Democratic Acts of Resistance and Collusion, Knowledge Cultures, 5 (3). 85-97.

White, E.J. \& Redder, B. (2019). Age-Responsive Pedagogies: 'Preschool' teachers interrogate their dialogues with and about two year-olds. Teaching, Wellington, NZ: Learning and Research Initiative (TLRI) http://www.tlri.org.nz/sites/default/files/proj ects/TLRI\%2oSummary_White\%26Redder.pdf.

White, E.J., Redder, B., Bennett S., Manser B., Geddes C., Hjorth C., \&Rogers A. (2019). Age-Responsive Pedagogies. https://www.waikato.ac.nz/age-responsivxvx. 